\title{
Self-Sufficient Formaldehyde-to-Methanol Conversion by Organometallic Formaldehyde Dismutase Mimic
}

\author{
Dominic van der Waals ${ }^{+}{ }^{[a]}$ Leo E. Heim ${ }^{+}{ }^{[a]}$ Simona Vallazza, ${ }^{[a]}$ Christian Gedig, ${ }^{[a]}$ Jan Deska, ${ }^{[b]}$ \\ and Martin H. G. Precht| ${ }^{*[a]}$
}

\begin{abstract}
The catalytic networks of methylotrophic organisms, featuring redox enzymes for the activation of onecarbon moieties, can serve as great inspiration in the development of novel homogeneously catalyzed pathways for the interconversion of $\mathrm{C}_{1}$ molecules at ambient conditions. An imidazolium-tagged arene-ruthenium complex was identified as an effective functional mimic of the bacterial formaldehyde dismutase, which provides a new and highly selective route for the conversion of formaldehyde to methanol in absence of any external reducing agents. Moreover, secondary amines are reductively methylated by the organometallic dismutase mimic in a redox self-sufficient manner with formaldehyde acting both as carbon source and reducing agent.
\end{abstract}

Methanol and formaldehyde are key platform chemicals that are industrially formed from syngas on a megaton scale. ${ }^{[1-3]}$ Currently, these reactions are carried out at high temperatures and pressures over various different heterogeneous catalysts. ${ }^{[4,5]}$ Milder reaction conditions for the conversion of onecarbon entities have been achieved using well-defined molecular metal catalysts. Therein, the most successful examples commonly focussed on highly oxidized starting materials, such as carbon dioxide and formic acid. In addition to well-developed $\mathrm{CO}_{2}$ to formate reduction protocols, ${ }^{[6-11]}$ both multi-metallic approaches ${ }^{[12]}$ and single-site catalyst systems ${ }^{[13-17]}$ have emerged en route to the homogeneously catalyzed methanol synthesis from $\mathrm{CO}_{2}$ in the past five years. Moreover, the methanol production was attempted by catalytic disproportionation of formic acid. Fighting against the favorable formate decomposition, ${ }^{[18]}$ in 2014 a ruthenium-triphos complex was reported to generate $\mathrm{MeOH}$ in up to $50 \%$ yield along with at least two equivalents of $\mathrm{CO}_{2} \cdot{ }^{[19]}$

[a] Dr. D. van der Waals, ${ }^{+}$L. E. Heim, ${ }^{+}$S. Vallazza, C. Gedig, Dr. M. H. G. Prechtl Department für Chemie, Universität zu Köln

Greinstrasse 6, 50939 Cologne (Germany)

E-mail:martin.precht!@uni-koeln.de

Homepage: http://catalysis.uni-koeln.de/

[b] Prof. Dr. J. Deska

Department of Chemistry, Aalto-yliopisto

Kemistintie 1, 02150 Espoo (Finland)

$\left.{ }^{+}\right]$These authors contributed equally to this work.

$\square$ Supporting information for this article is available on the WWW under http://dx.doi.org/10.1002/chem.201602679.
In nature, formaldehyde plays a much more pronounced role within the family of $C_{1}$ molecules. Based on an evolutionary conserved detoxification mechanism, various methanol-tolerant or even methanol-feeding microorganisms have developed a biocatalytic machinery to deal with, and benefit from formalin. In addition to the capability to include formaldehyde into the biosynthetic carbon fixation by the ribulose monophosphate pathway, ${ }^{[20,21]}$ methylotrophs exploit formalin, rather than methanol, as a source of reduction equivalents. Therein, the preactivation of $\mathrm{CH}_{2} \mathrm{O}$ by the formation of hemithioacetal conjugates with either cofactors (mycothiol or glutathione) ${ }^{[22,23]}$ or protein-bound mercaptanes ${ }^{[24]}$ allows for a transfer hydrogenation to $\mathrm{NAD}^{+}$, in which $\mathrm{NADH}$ is liberated to serve as biological reductant (Scheme 1, top left). Inspired by this mode of action, we recently reported on a biomimetic ruthenium-based $\mathrm{H}_{2}$ release system using methanediol as simple tetrahedral formaldehyde conjugate analogue and hydrogen as abiotic $\mathrm{NADH}$ equivalent (Scheme 1, bottom left). ${ }^{[25]}$

A great number of $C_{1}$-feeding bacterial strains, for example Pseudomonas putida, Staphylococcus aureus, or Mycobacterium

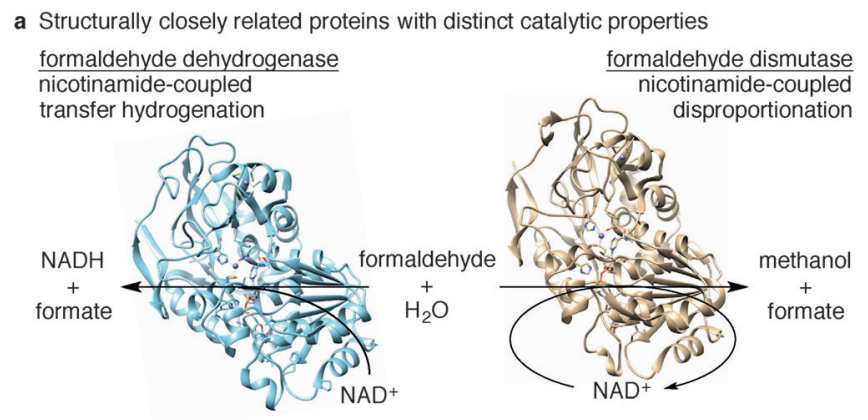

b Catalytic bifurcation in the ruthenium-mediated formaldehyde decomposition formaldehyde dehydrogenase mimic formaldehyde dismutase mimic acceptorless $\mathrm{H}_{2}$ release $\quad$ hydride-coupled acceptorless $\mathrm{H}_{2}$ release $\begin{array}{r}\text { hydride-coupled } \\ \text { disproportionation }\end{array}$

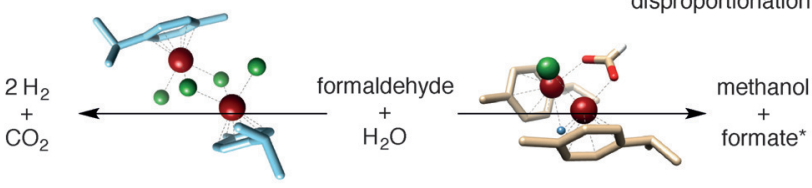
Nat. Commun. 2014, 5, 3621

this work

Scheme 1. a) The primary routes of the biological formaldehyde metabolism proceed by dehydrogenation and disproportionation by two structurally linked nicotinamide-depending oxidoreductases. b) Bioinspired rutheniumcatalysed $\mathrm{H}_{2}$ release and methanol synthesis from hydrated formaldehyde. * Formate serves as second reduction equivalent for the conversion of formaldehyde to methanol under liberation of $\mathrm{CO}_{2}$. 
gastri, supplement their formaldehyde metabolism by a second pathway using dismutases that are independent of external sacrificial redox partners (Scheme 1, top right). ${ }^{[26-28]}$ On one side, these formalin disproportionating enzymes exhibit a considerable structural and functional resemblance of glutathione-independent zinc-containing dehydrogenases, with a sequence similarity greater $70 \%$ (Supplementary Figure 1 in the Supporting Information). ${ }^{[29]}$ As a result of a firmly immobilized nicotinamide-dinucleotide cofactor inside the active site, ${ }^{[30,31]}$ however, initial dehydrogenation of the conjugated formalin is accompanied by a reduction of a second formaldehyde moiety. Hence, the deviated catalytic behavior provides both methanol and formate from two molecules of formaldehyde and water. Considering the analogy of $\mathrm{NADH}$ as biological hydrogen carrier and our lately described bioinspired process featuring an acceptorless $\mathrm{H}_{2}$ liberation, ${ }^{[25]}$ we envisioned that modification of the organometallic species and/or the reaction environment of our original protocol will lead to a novel homogeneously catalyzed formaldehyde-to-methanol converting system, (Scheme 1, bottom right) yet unprecedented in the context of abiotic $C_{1}$-valorization pathways. ${ }^{[32,33]}$

Recently, we reported on the possibility to incorporate a ruthenium-based formaldehyde dehydrogenase mimic into an artificial metabolism, which nicely cooperates with methanol-activating enzymes to provide a room-temperature pathway for the $\mathrm{MeOH}$ to $\mathrm{H}_{2}$ conversion and showcases the potential of chemoenzymatics in the small molecule activation. ${ }^{[34]}$ However, in our crimp-top setup for the in situ gas phase analysis, the apparent turnover numbers of the $\mathrm{H}_{2}$ liberation in aqueous phosphate buffer lagged behind the uncoupled system, which can in parts be attributed to infavourable metal-protein interactions, or might be related to the reversibility of the process by the formalin reduction under elevated $\mathrm{H}_{2}$ pressure. This finding served as a starting point for the redirection of the catalytic profile towards a formaldehyde dismutase mimic that is disclosed in this communication.

To our delight, already slight modifications of our parent $\left[\mathrm{Ru}(p \text {-cymene }) \mathrm{Cl}_{2}\right]_{2}$ catalysed $\mathrm{H}_{2}$ release protocol, namely a closed-vessel system and increased reaction temperatures, resulted in a functional dismutase mechanism. Further optimizations, with regard to the nature and stoichiometry of the additives, led to an efficient catalytic disproportionation (Supplementary Table 1-3). While initial attempts provided methanol from paraformaldehyde in a 1:1 stoichiometry, formalin decomposition with $1 \mathrm{~mol} \%$ of $\left[\mathrm{Ru}(p \text {-cymene }) \mathrm{Cl}_{2}\right]_{2}$ at $80^{\circ} \mathrm{C}$ in phosphate buffer $(0.4 \mathrm{~m}, \mathrm{pH} 6)$ proceeded with increased $\mathrm{MeOH}$ yields $(75 \%)$ as a result of the formate dehydrogenation, which allows for the reduction of a second formaldehyde equivalent. ${ }^{[35]}$ For the primary disproportionation, various mechanisms can be assumed (Scheme 2). Hence, studies aiming to elucidate the actual catalytic pathway have been conducted.

Hydrolysis of paraformaldehyde would, in any of our proposals, lead to free formaldehyde in equilibrium with its hydrated form methanediol. Initial investigations of the $\mathrm{pH}$ dependency of the reaction quickly revealed that the ruthenium-independent Cannizzaro-type disproportionation appears only as a background reaction at $\mathrm{pH}$ values greater than 9.5 (Supplementary

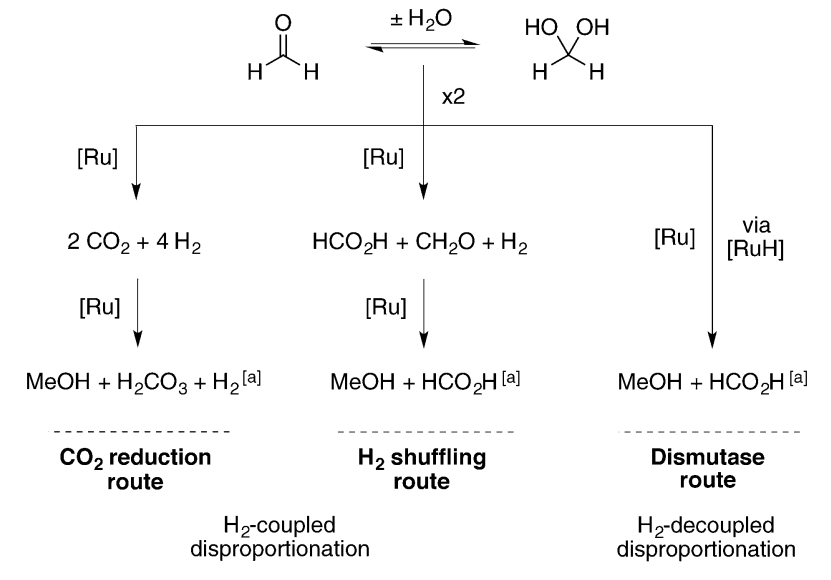

Scheme 2. Proposed routes for the catalytic formaldehyde disproportionation based on $\mathrm{H}_{2}$ coupled dehydrogenation/hydrogenation pathways or the dismutase-like catalysis by intermediary hydride species. [a] $\mathrm{H}_{2} / \mathrm{HCO}_{2} \mathrm{H}$ can potentially act as reducing agents for another equivalent of formaldehyde.

Table 4) and, thus, cannot be considered as a productive pathway. Under the assumption that free $\mathrm{H}_{2}$ is involved as redox mediator, two hydrogen-coupled routes are feasible. As methanediol has been shown to readily dehydrogenate to yield $\mathrm{CO}_{2}$ and $\mathrm{H}_{2}$, it was considered that in a closed system the direct reduction of $\mathrm{CO}_{2}$ to methanol might be occurring (Scheme 2, left). However, neither precharging of the reaction vessel with carbon dioxide nor the removal of superfluous $\mathrm{CO}_{2}$ by $\mathrm{Ca}(\mathrm{OH})_{2}$ resulted in measurable effects on the methanol yields (Supplementary Table 5). This suggests that the direct $\mathrm{CO}_{2}$ reduction might not be the primary mechanism for the methanol formation. Additionally, the dismutation of ${ }^{13} \mathrm{C}$-labelled paraformaldehyde was conducted under elevated pressure of ${ }^{12} \mathrm{CO}_{2}$ to get further insight into the potential role of carbon dioxide. While the yields were not affected by the level of $\mathrm{CO}_{2}$ in the pressurized atmosphere (Supplementary Table 6), the ${ }^{1} \mathrm{H}$ NMR spectroscopical analysis of the methanol obtained from the ${ }^{13} \mathrm{CH}_{2} \mathrm{O}$ disproportionation under 15 bar ${ }^{12} \mathrm{CO}_{2}$ provided no significant evidence of the ${ }^{12} \mathrm{CH}_{3} \mathrm{OH}$ formation (Supplementary Figure 2), suggesting that carbon dioxide was not incorporated from the overlaying atmosphere by a $\mathrm{CO}_{2}$ reduction pathway (Scheme 3).

In an alternative route, the methanol formation could result from the direct reduction of formaldehyde, either by another hydrogen-coupled process exploiting free $\mathrm{H}_{2}$ as redox mediator (Scheme 2, centre), or by the dismutase-like dehydrogenative generation of reducing ruthenium-hydride species from the tetrahedral formalin (Scheme 2, right). Examination of the reaction gas phase by pressure monitoring and headspace GC-

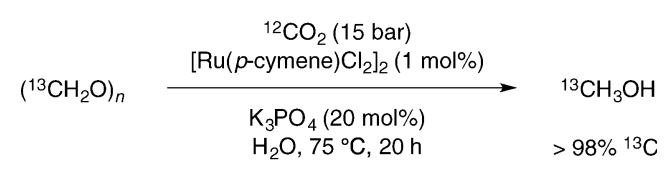

no carbon scrambling $=\mathrm{CO}_{2}$ reduction route disproved

Scheme $3 .{ }^{13} \mathrm{C}$-Labelling experiment to exclude the possibility of carbon dioxide as formal disproportionation intermediate. 
TCD (gas chromatography with a thermal conductivity detector) analysis gave a clear evidence for the formation of hydrogen gas in the initial period of the process. To our delight, we found that the formalin disproportionation was also taking place in an open flask setup rather than in an autoclave, in which strikingly high yields of methanol were achieved even under constant removal of the gas phase by argon purging (Scheme $4 \mathrm{a}$ ). Further confirmation of a $\mathrm{H}_{2}$-decoupled pathway

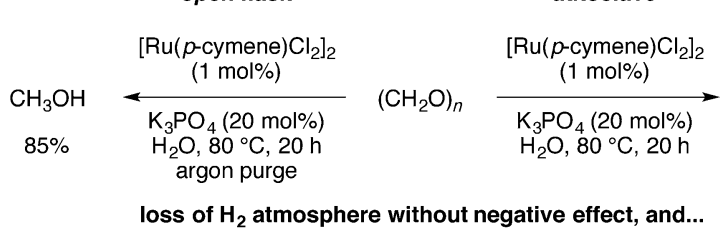

\begin{tabular}{ccc}
$\mathrm{H}_{2}(0.5 \mathrm{bar})$ & \\
$\left(\mathrm{CD}_{2} \mathrm{O}\right)_{n}$ & $\stackrel{\left[\mathrm{Ru}(p \text {-cymene }) \mathrm{Cl}_{2}\right]_{2}(1 \mathrm{~mol} \%)}{\mathrm{K}}$ & $\mathrm{CD}_{3} \mathrm{OD}+\mathrm{HCD}_{2} \mathrm{OD}$ \\
\cline { 2 - 2 } & $\mathrm{K}_{3} \mathrm{PO}_{4}(20 \mathrm{~mol} \%)$ & $98: 2$
\end{tabular}

... no H/D-scrambling $=\mathrm{H}_{2}$-coupled disproportionation disproved

Scheme 4. Gas phase removal and deuterium labelling experiments to elucidate the role of $\mathrm{H}_{2}$ gas as potential redox mediator.

was obtained from the results of the ruthenium-catalyzed dismutation of deuterated formaldehyde $\left(\mathrm{CD}_{2} \mathrm{O}\right)_{n}$ under $\mathrm{H}_{2}$ pressure. Therein, less than $2 \%$ of the partially hydrogen-containing methanol $\left(\mathrm{HCD}_{2} \mathrm{OD}\right)$ were detected, which reflects exactly the isotopologic composition of the commercial $\left(\mathrm{CD}_{2} \mathrm{O}\right)_{n}$ used as starting material in this experiment (Supplementary Figure 3). The complete absence of H/D scrambling under the mixed $H_{2} / D_{2}$ atmosphere can serve as a strong endorsement for the disproval of the involvement of any gaseous redox mediators (Scheme $4 \mathrm{~b}$ ). Hence, the ruthenium-catalysed formalin disproportionation is most likely to proceed by a truly dismutase-like mechanism with a catalyst-bound hydride mimicking the intimate enzyme-nicotinamide arrangement. A catalytically potent dimeric hydride complex has been isolated and characterized (Figure 1). ${ }^{[35]}$

At first glance, these findings somewhat contradicted our previous report on the acceptorless $\mathrm{H}_{2}$ production from formalin employing a very similar catalyst system. However, close inspection of all parameters exposed the hidden key for this catalytic bifurcation. As introduced during our attempt to exploit the ruthenium-based dehydrogenase mimic in a chemoenzymatic approach, ${ }^{[34]}$ the phosphate-containing reaction medium proved to have a major influence on the behavior of the dimeric ruthenium catalyst. As opposed to the formalin dehydrogenation by $\left[\mathrm{Ru}\left(p \text {-cymene) } \mathrm{Cl}_{2}\right]_{2}\right.$ in absence (or at low concentrations) of phosphate, which led to a strong and constant rise in pressure, already $20 \mathrm{~mol} \%$ of $\mathrm{K}_{3} \mathrm{PO}_{4}$ substantially reduced the initial hydrogen formation that quickly came to a complete rest at approximately $5 \%$ conversion (Supplementary Figure 4,5). In situ analysis of the optimized dismutation process by NMR spectroscopy and headspace GC-TCD analysis

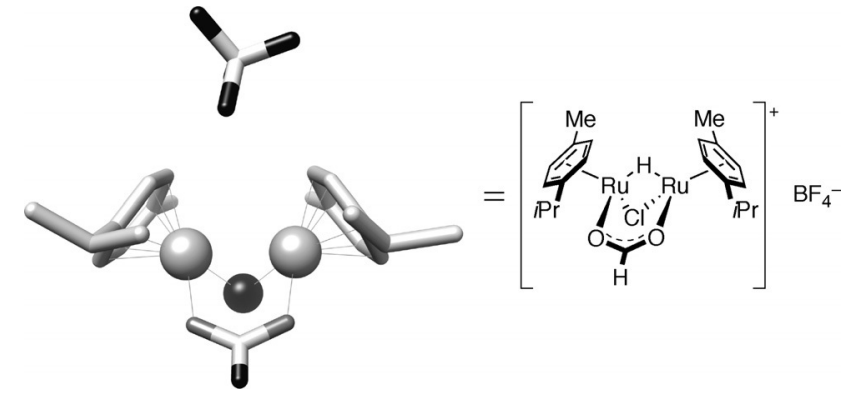

Figure 1. Crystallization of in situ formed formiato-bridged ruthenium dimers was achieved by precipitation as tetrafluoroborate salt. Crystal structure analysis shows a symmetric arrangement of the cymene donors with both formate and chloride as bridging ligands. Although X-ray diffraction could not help to allocate the hydridic hydrogen between the two ruthenium centres, clear evidence for the hydride nature of the complex was obtained by spectroscopic and spectrometric methods. ${ }^{[25]}$ For detailed crystallographic data see the Supporting Information and ref. [35].

also revealed the rapid buildup of methanol, formate, and $\mathrm{H}_{2}$ during the first minutes. However, only the methanol production continued steadily over hours, explaining the good selectivity observed in the formalin decomposition (Figure 2).

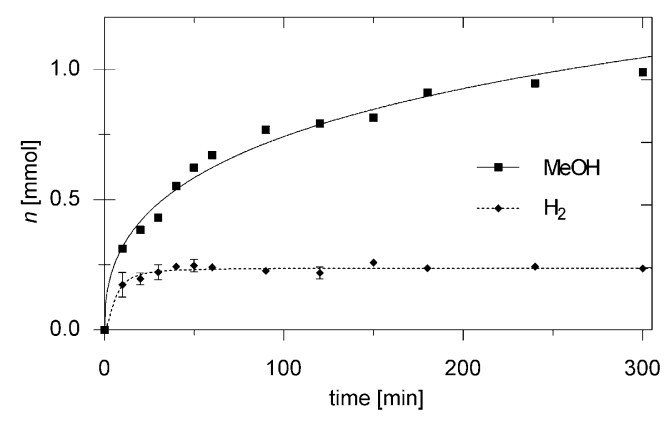

Figure 2. Constant methanol formation versus discontinuous $\mathrm{H}_{2}$ release.

While the underlying role of the phosphate additive still remains unclear and its elucidation will require a much deeper investigation, we expected that further fine-tuning of the reaction conditions would already allow us to provide a highly efficient formaldehyde-to-methanol procedure. To also determine the effect that modifications to the ruthenium precatalyst impart upon the methanol yield of the reaction (Supplementary table 7), a range of complexes analogous to the commercial $\left[\mathrm{Ru}(p \text {-cymene }) \mathrm{Cl}_{2}\right]_{2}$ were synthesized employing a recently developed microwave-assisted protocol. ${ }^{[36]}$ In the dismutation, variation of the anionic counterion by different (pseudo)halides showed no influence on the reaction rates or the methanol yield after $20 \mathrm{~h}$ (Table 1, Entries 1-4), which is in good agreement with the previously described exchange of bridging ligands during the methanediol dehydrogenation. ${ }^{[24]}$ In contrast, the substitution pattern and particularly the polarity of the arene ligand proved to be decisive for the activity of the methanol-generating process. While more hydrophobic $\eta^{6}$ donors led to decreased final concentrations of the alcohol (Table 1, Entry 6), decoration of the arene by polar hydroxy groups, to 


\begin{tabular}{|c|c|c|c|c|c|}
\hline \multirow{2}{*}{\multicolumn{2}{|c|}{$3\left(\mathrm{CH}_{2} \mathrm{O}\right)_{n}+n \mathrm{H}_{2} \mathrm{O}$}} & \multirow{2}{*}{\multicolumn{2}{|c|}{$\begin{array}{c}{\left[\mathrm{Ru}(\text { arene }) X_{2}\right]_{2}(1 \mathrm{~mol} \%)} \\
\mathrm{K}_{3} \mathrm{PO}_{4}(20 \mathrm{~mol} \%) \\
\mathrm{H}_{2} \mathrm{O}, T, 20 \mathrm{~h}\end{array}$}} & \multirow{2}{*}{\multicolumn{2}{|c|}{$2 n \mathrm{CH}_{3} \mathrm{OH}+n \mathrm{CO}$}} \\
\hline & & & & & \\
\hline Entry & Arene & & $x$ & $\begin{array}{l}T \\
{\left[{ }^{\circ} \mathrm{C}\right]}\end{array}$ & $\begin{array}{l}\text { Yield }^{[b]} \\
{[\%]}\end{array}$ \\
\hline 1 & \multicolumn{2}{|l|}{ p-cymene } & $\mathrm{Cl}$ & 80 & 75 \\
\hline 2 & \multicolumn{2}{|c|}{$p$-cymene } & $\mathrm{Br}$ & 80 & 68 \\
\hline 3 & \multicolumn{2}{|l|}{ p-cymene } & 1 & 80 & 66 \\
\hline 4 & \multicolumn{2}{|c|}{ p-cymene } & $\mathrm{SCN}$ & 80 & 68 \\
\hline 5 & \multicolumn{2}{|l|}{ toluene } & $\mathrm{Cl}$ & 80 & 70 \\
\hline 6 & \multicolumn{2}{|c|}{ hexamethylbenzene } & $\mathrm{Cl}$ & 80 & 50 \\
\hline 7 & \multicolumn{2}{|c|}{ 2-phenylethanol } & $\mathrm{Cl}$ & 80 & 73 \\
\hline 8 & \multicolumn{2}{|c|}{ 2-phenoxyethanol } & $\mathrm{Cl}$ & 80 & 79 \\
\hline 9 & & & $\mathrm{Cl}$ & 80 & 93 \\
\hline \multirow[t]{2}{*}{10} & \multirow{2}{*}{\multicolumn{3}{|c|}{$\mathrm{Cl}^{-} \quad[\mathrm{Ru}]$}} & 25 & 58 \\
\hline & & & & & \\
\hline
\end{tabular}

[a] Reactions run on a $2 \mathrm{mmol}$ scale in aqueous phosphate buffer $(1 \mathrm{~mL}$, $0.4 \mathrm{M}, \mathrm{pH} 6$ ). [b] Conversions to methanol were determined by ${ }^{1} \mathrm{H}$ NMR spectroscopy relative to 1,4-dioxane as internal standard. All values are normalized to the reaction stoichiometry, only allowing a maximum of $67 \%$ methanol.

facilitate the aqueous solubility, resulted in slightly improved catalytic systems (Table 1, Entries 7,8). By incorporation of a cationic 1,2-dimethylimidazolium unit, ${ }^{[37]}$ a highly active ruthenium precatalyst was obtained that showed excellent performance in the formalin dismutation with a final methanol yield of $93 \%$ (Table 1, Entry 9) along with deteriorated dehydrogenation properties (Supplementary Figure 6). More importantly, the imidazolium-tagged dimer still exhibited a good activity at considerably lower temperatures with a reasonable conversion even at room temperature (Table 1, Entry 10). For this most reactive dismutase mimic, turnover frequencies up to $1060 \mathrm{~h}^{-1}$ were recorded and a significant methanol formation was detected at ruthenium-loadings as low as 250 ppm (Supplementary Table 8).

Currently, there is a significant focus on environmentally benign methods for chemical procedures and in particular on the use of recyclable catalysts. Initial recharge experiments employing the commercial cymene-ruthenium dimer already revealed a stable catalytic system with considerable activity over at least two successive formaldehyde recharges (Table 2). In subsequent cycles, the aqueous phase was replaced by an untreated formalin/phosphate solution and 1-butyl-3-methylimidazolium bis(trifluoromethanesulfonyl)imide ([bmim] $\mathrm{NTf}_{2}$ ) was used as co-phase, in which a substantially higher long-term stability of the catalyst was achieved compared to the other ionic liquids tested so far (Figure 3). Nonetheless, there remains a need for further investigations on the ionic liquid-based recycling systems, and in-depth studies to identify an optimal methodology are currently ongoing.

Based on the proposal that the methanol formation occurred through reduction of free formaldehyde, the possibility of the in situ formation, and hydrogenations of even more reactive methylene compounds by condensation with the aldehyde, appeared as valuable synthetic extensions of the dispro-

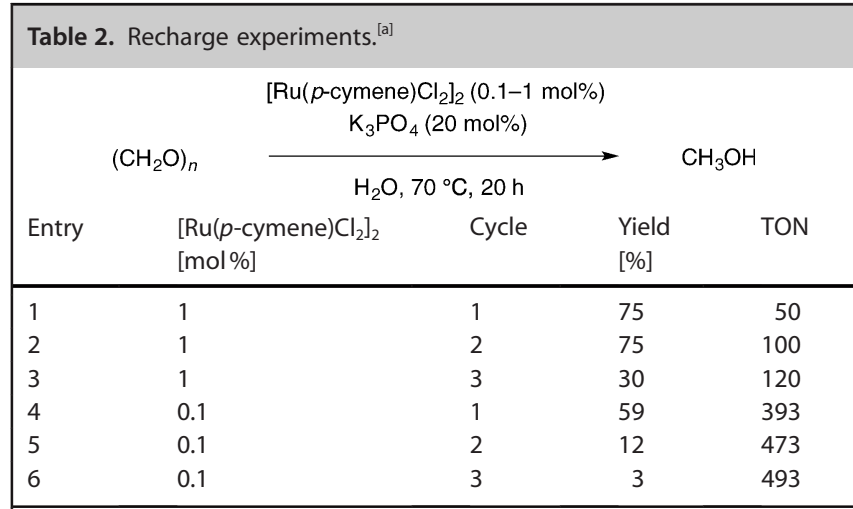

[a] Reactions run on a $4 \mathrm{mmol}$ scale in water $(2 \mathrm{~mL})$ in a sealed autoclave. Final concentrations of methanol were determined by ${ }^{1} \mathrm{H}$ NMR spectroscopy relative to 1,4-dioxane as internal standard. After each cycle, all volatiles were removed in vacuo, and paraformaldehyde, water, and dioxane were replaced.

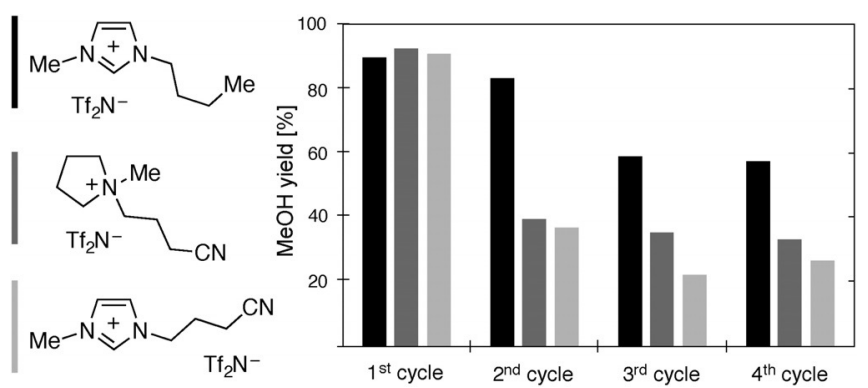

Figure 3. Recycling of the imidazolium-tagged arene-ruthenium dimer using nonwater-miscible ionic liquids as additives for the biphasic formaldehydeto-methanol conversion.

portionation protocol. Initial attempts focused on secondary amines as additional reaction partners to study the redox selfsufficient reductive amination employing formaldehyde both as carbon source and reducing agent. ${ }^{[38]}$ To our delight, the methylation of cyclic secondary amines proceeded smoothly in the presence of $0.5 \mathrm{~mol} \%$ of the dimeric cymene-ruthenium chloride with excellent yields of $\mathrm{N}$-methylpiperidine and $\mathrm{N}$ methylmorpholine after only $2 \mathrm{~h}$ of $81 \%$ and $69 \%$, respectively (Scheme 5). Opening up an entirely new perspective on the formalin redox chemistry, future investigations will cover the synthetic aspects of the formaldehyde decomposition in much greater detail.

In conclusion, we herein describe a new, homogeneously catalyzed, selective formaldehyde-to-methanol transformation as a missing piece in the $C_{1}$-interconversion puzzle. Inspired by bacterial formaldehyde dismutase biocatalysts using areneruthenium complexes as activating species, it was shown that the reaction proceeds by a formaldehyde reduction by metal-

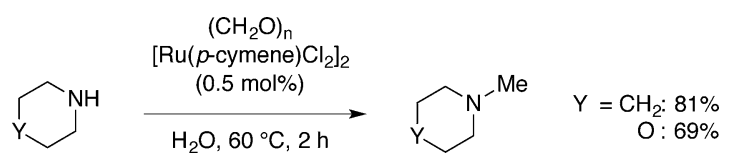

Scheme 5. Redox self-sufficient reductive N-methylation. 
bound hydrogen species as redox cofactor analogues, rather than through $\mathrm{CO}_{2}$ hydrogenation, formate decomposition, or the Cannizzaro disproportionation. An imidazolium-tagged ruthenium complex did not only exhibit optimal catalytic properties, but further allowed for the construction of biphasic reaction setups that make use of ionic liquids for an easy catalyst recycling. In addition, the metal-mediated formalin decomposition could be employed in a synthetic manner, in which formaldehyde acts as a sole stoichiometric reagent in a redox selfsufficient reductive methylation of secondary amines.

\section{Experimental Section}

General remarks. All chemicals were used without further purification, primarily from Sigma Aldrich or Strem Chemicals. Paraformaldehyde was purchased from Acros Organics (>95\% Extra Pure), HPLC grade water was used as solvent without degassing. $\left({ }^{13} \mathrm{CH}_{2} \mathrm{O}\right)_{n}$ was obtained from the Cambridge Isotope Laboratories and $\left(\mathrm{CD}_{2} \mathrm{O}\right)_{n}$ from Sigma Aldrich. ${ }^{1} \mathrm{H}$ and ${ }^{13} \mathrm{C}$ NMR spectra were recorded in $\mathrm{CDCl}_{3}$ or $\mathrm{D}_{2} \mathrm{O}(\geq 99.5 \%$ deuterated, purchased from Fluorochem) on a Bruker Avance $300(300 \mathrm{MHz})$. All chemical shifts $(\delta)$ are reported as parts per million (ppm) with reference to tetramethylsilane (TMS) $(\delta=0.00 \mathrm{ppm})$ unless otherwise stated. Selectivities for the methanol production are given as percentage relative to the maximum paraformaldehyde conversion (ca. 67\%) as an internal standard and are the average of at least two runs unless otherwise mentioned. Headspace gas chromatography equipped with a TCD was carried out on a Thermo Fischer Scientific GC-TCD.

General procedure for the ruthenium-catalyzed formaldehyde dismutation. To a glass screw capped reaction vial $(20 \mathrm{~mL})$ furnished with a stirrer, $\left[\mathrm{Ru}\left(1-\text { phenethyl-2,3-dimethylimidazolium) } \mathrm{Cl}_{3}\right]_{2}\right.$ $(16 \mathrm{mg}, 0.02 \mathrm{mmol})$ and paraformaldehyde ( $p F A)(60 \mathrm{mg}, 2.0 \mathrm{mmol})$ were added. $\mathrm{K}_{3} \mathrm{PO}_{4}(8 \mathrm{mg}, 0.4 \mathrm{mmol})$ and the 1,4-dioxane standard were added, followed by HPLC grade water $(2 \mathrm{~mL})$. Afterwards, the reaction vial was sealed and heated to the desired temperature for the respective reaction duration under constant stirring. Upon completion, the reaction was cooled, shaken to ensure homogeneity, and an aliquot was taken directly for NMR analysis after dilution with $\mathrm{D}_{2} \mathrm{O}$.

General procedure for the ruthenium-catalyzed N-methylation. Paraformaldehyde $(300 \mathrm{mg}, 10 \mathrm{mmol})$ and $\left[\mathrm{Ru}(p \text {-cymene }) \mathrm{Cl}_{2}\right]_{2}$ $(6.1 \mathrm{mg}, 0.01 \mathrm{mmol})$ were placed in a screw-neck vial, followed by the addition of water $(1 \mathrm{~mL})$, and the secondary amine (piperidine, $170 \mathrm{mg}, 2.0 \mathrm{mmol}$ or morpholine ( $174 \mathrm{mg}, 2.0 \mathrm{mmol}$ ). The vial was closed, then placed in a preheated aluminium block $\left(60^{\circ} \mathrm{C}\right)$ and stirred for $2 \mathrm{~h}$. Afterwards, the vial was cooled to room temperature, aqueous $\mathrm{NaOH}(2 \mathrm{M}, 2 \mathrm{~mL})$ was added, and the aqueous phase was washed with $\mathrm{DCM}(3 \times 10 \mathrm{~mL})$. The combined organic fractions were dried over $\mathrm{MgSO}_{4}$ and $\mathrm{Al}_{2} \mathrm{O}_{3}$, and the solvent was removed in vacuo to yield the desired amine ( $\mathrm{N}$-methylpiperidine, $160 \mathrm{mg}, 1.62 \mathrm{mmol}, 81 \%$; or $\mathrm{N}$-methylmorpholine, $140 \mathrm{mg}$, $1.38 \mathrm{mmol}, 69 \%)$.

\section{Acknowledgements}

We gratefully acknowledge financial support provided by the Ministerium für Innovation, Wissenschaft und Forschung (NRWreturnee award 2009 to M.H.G.P.), the Deutsche Forschungsgemeinschaft (Heisenberg-Program), the COST (Catalytic Routines for Small Molecule Activation, CARISMA), the Ernst-
Haage-Stiftung (Max-Planck Society), and the Alexander-vonHumboldt Foundation (Connect! program). Our special thanks go to Svetlana Botov and Hagga Schmalz for the access to the GC-TCD.

Keywords: biocatalysis - ionic liquids - methanol $\cdot$ reductive methylation $\cdot$ ruthenium

[1] W. Wang, S. Wang, X. Ma, J. Gong, Chem. Soc. Rev. 2011, 40, 3703-3727.

[2] A. M. Bahmanpour, A. Hoadley, A. Tanksale, Rev. Chem. Eng. 2014, 30, $583-604$.

[3] B. Sam, B. Breit, M. J. Krische, Angew. Chem. Int. Ed. 2015, 54, 3267 3274; Angew. Chem. 2015, 127, 3317-3325.

[4] E. Alberico, M. Nielsen, Chem. Commun. 2015, 51, 6714-6725.

[5] S. Saeidi, N. A. S. Amin, M. R. Rahimpour, J. CO2 Util. 2014, 5, 66-81.

[6] S. Moret, P. J. Dyson, G. Laurenczy, Nat. Commun. 2014, 5, 4017.

[7] R. Tanaka, M. Yamashita, K. Nozaki, J. Am. Chem. Soc. 2009, 131, 14168 14169.

[8] K. Angermund, W. Baumann, E. Dinjus, R. Fornika, H. Görls, M. Kessler, C. Krüger, W. Leitner, F. Lutz, Chem. Eur. J. 1997, 3, 755-764.

[9] P. G. Jessop, Y. Hsiao, T. Ikariya, R. Noyori, J. Am. Chem. Soc. 1996, 118, $344-355$.

[10] P. Jessop, T. Ikariya, R. Noyori, Nature 1994, 368, 231-233.

[11] E. Graf, W. Leitner, J. Chem. Soc., Chem. Commun. 1992, 623-624.

[12] C. A. Huff, M. S. Sanford, J. Am. Chem. Soc. 2011, 133, 18122-18125.

[13] C. A. Huff, M. Sanford, ACS Catal. 2013, 3, 2412-2416.

[14] E. Balaraman, C. Gunanathan, J. Zhang, L. J. W. Shimon, D. Milstein, Nat. Chem. 2011, 3, 609-614.

[15] S. Wesselbaum, T. vom Stein, J. Klankermayer, W. Leitner, Angew. Chem. Int. Ed. 2012, 51, 7499-7502; Angew. Chem. 2012, 124, 7617-7620.

[16] S. Wesselbaum, V. Moha, M. Meuresch, S. Brosinski, K. M. Thenert, J. Kothe, T. vom Stein, U. Englert, M. Hölscher, J. Klankermayer, W. Leitner, Chem. Sci. 2015, 6, 693-704.

[17] A. J. M. Miller, D. M. Heinekey, J. M. Mayer, K. I. Goldberg, Angew. Chem. Int. Ed. 2013, 52, 3981-3984; Angew. Chem. 2013, 125, 4073-4076.

[18] T. J. Korstanje, J. I. van der Vlugt, C. J. Elsevier, B. de Bruin, Science 2015, $350,298-320$.

[19] S. Savourey, G. Lefèvre, J.-C. Berthet, P. Thuéry, C. Genre, T. Cantat, Angew. Chem. Int. Ed. 2014, 53, 10466-10470; Angew. Chem. 2014, 126, $10634-10638$.

[20] H. Yurimoto, N. Kato, Y. Sakai, Chem. Rec. 2005, 5, 367-375.

[21] S. Witthoff, K. Schmitz, S. Niedenführ, K. Nöh, S. Noack, M. Bott, J. Marienhagen, Appl. Environ. Microbiol. 2015, 81, 2215-2225.

[22] A. Norin, P. W. van Ophem, S. R. Piersma, B. Persson, J. A. Duine, H. Jörnwall, Eur. J. Biochem. 1997, 248, 282-289.

[23] J. Ras, P. W. van Ophem, W. N. Reijnders, R. J. van Spanning, J. A. Duine, A. H. Stouthamer, N. Harms, J. Bacteriol. 1995, 177, $247-251$.

[24] D. Tsuru, N. Oda, Y. Matsuo, S. Ishikawa, K. Ito, T. Yoshimoto, Biosci. Biotechnol. Biochem. 1997, 61, 1354-1357.

[25] L. E. Heim, N. E. Schlörer, J.-H. Choi, M. H. G. Prechtl, Nat. Commun. 2014, 5, 3621.

[26] N. Kato, K. Shirakawa, H. Kobayashi, C. Sakazawa, Agric. Biol. Chem. $1983,47,39-46$.

[27] L. V. Bystrykh, N. I. Govorukhina, P. W. van Ophem, H. J. Hektor, L. Dijkhuizen, J. A. Duine, J. Gen. Microbiol. 1993, 139, 1979-1985.

[28] H. Yanase, H. Noda, K. Aoki, K. Kita, N. Kato, Biosci. Biotechnol. Biochem. 1995, 59, 197- 202.

[29] Comparison of sequences obtained from the RCSB protein data bank (PDB) data for formaldehyde dehydrogenase (1KOL): a) N. Tanaka, Y. Kusakabe, K. Ito, T. Yoshimoto, K. T. Nakamura, J. Mol. Biol. 2002, 324, 519 533; and formaldehyde dismutase (2DPH): b) T. Hasegawa, A. Yamano, K. Miura, Y. Katsube, H. Yanase, N. Kato, Acta Crystallogr. Sect. A 2002, $58, \mathrm{c} 102$.

[30] N. Kato, T. Yamagami, M. Shimao, C. Sakazawa, Eur. J. Biochem. 1986, $156,59-64$.

[31] R. P. Mason, J. K. M. Sanders, Biochemistry 1989, 28, 2160-2168. 
[32] For the catalytic disproportionation of higher aldehydes, see: M. Bianchi, U. Matteoli, G. Menchi, P. Frediani, F. Piacenti, J. Organomet. Chem. 1982, 240, 65-70.

[33] For a ruthenium-catalyzed Tishchenko-type disproportionation, see: M.O. Simon, S. Darses, Adv. Synth. Catal. 2009, 351, 153.

[34] L. E. Heim, D. Thiel, C. Gedig, J. Deska, M. H. G. Prechtl, Angew. Chem. Int. Ed. 2015, 54, 10308-10312; Angew. Chem. 2015, 127, 10447-10451.

[35] As a result of the 2:1 stoichiometry of the reaction (1 equiv of $\mathrm{CH}_{2} \mathrm{O}$ giving 0.67 equiv $\mathrm{MeOH}$ and 0.33 equiv of $\mathrm{CO}_{2}$, the yields reported herein are normalized to the maximum outcome of 0.67 equiv). For the crystal structure of the synthesized ruthenium complex, see: CCDC 1471617 contain the supplementary crystallographic data for this paper. These data are provided free of charge by The Cambridge Crystallographic Data Centre

[36] L. E. Heim, S. Vallazza, D. van der Waals, M. H. G. Prechtl, Green Chem. 2016, 18, 1469-1474.

[37] T. J. Geldbach, P. J. Dyson, J. Am. Chem. Soc. 2004, 126, 8114-8115.

[38] For a formate-dependent methylation of anilines, see: S. Savourey, G. Lefèvre, J.-C. Berthet, T. Cantat, Chem. Commun. 2014, 50, 14033 14036.

Received: June 6, 2016

Published online on July 6, 2016 